established is strong, not least because their condition is closely observed, unlike self-medication with patent remedies.

There are, however, two more arguments for continuation studies which are often overlooked. Whether or not the drug produces an immediate improvement, the critical question remains its effect on the course of the disease. A patient sample who have been on placebo for six months and then start the active preparation can be compared with those who have been on the active preparation throughout, thereby allowing one to judge whether they catch up (i.e. the drug has no effect on the course) or not. An important question can be answered provided double-blind randomisation is maintained, although it could be argued that this would only justify continuation studies lasting three months. The second scientific justification is the need to monitor later side-effects which, though unlikely, need to be established before a drug is released for continuous use over the five-year course of a case of dementia.

One might suggest that a continuation open label study after a double-blind placebo controlled study on patients with Alzheimer's disease is an ethical necessity and not an ethical transgression.

\section{Reference}

HIRSCH, S. \& SPENCE, S. (1995) Ethical approaches to researching the mentally incapable patient. Psychiatric Bulletin, 19, 414-416.

John M. Kellett, Consultant and Senior Lecturer in Psychiatry of Old Age, St George's Hospital, Blackshaw Road, London SW17 OQT

\title{
Shoes and souls
}

\author{
Mani Rajagopalan
}

I would love to be in your shoes;

Asking me questions I can't understand.

Telling me things I won't hear,

And soaking my brain with neuroleptic fluids.

How would you know what it's like?

To talk to people you cannot see

To listen to voices you don't want to hear

And to hate people you know you love?

Would you care enough to stay silent, And listen to the anguish of a troubled soul?
To share the myriad feelings within me, And to walk with me out of this hell?

But then you have your own concerns; Dopamine receptors are far more fascinating, And I'm just a case report on your CV. I would love to be in your shoes.

Mani Rajagopalan, Department of Psychiatry. Christian Medical College, Vellore 632002, India 